Article

\title{
Integrated Health Interventions for Improved Livelihoods: A Case Study in Ethiopia
}

\author{
Menale Kassie ${ }^{1, *(\mathbb{D}}$, Zewdu Abro ${ }^{2}{ }^{\mathbb{D}}$, Tesfamicheal Wossen ${ }^{3}$, Samuel T. Ledermann ${ }^{4}$, \\ Gracious Diiro ${ }^{1}$, Shifa Ballo ${ }^{2}$ and Lulseged Belayhun ${ }^{2}$ \\ 1 International Centre of Insect Physiology and Ecology (icipe), P.O.Box 30772-00100 Nairobi, Kenya; \\ gdiiro@icipe.org \\ 2 International Centre of Insect Physiology and Ecology (icipe), P.O.Box 5689 Addis Ababa, Ethiopia; \\ zabro@icipe.org (Z.A.); sballo@icipe.org (S.B.); lbelayhun@icipe.org (L.B.) \\ 3 International Institute of Tropical Agriculture (IITA), P.O.Box 30709-00100 Nairobi, Kenya; \\ T.Assfaw@cgiar.org \\ 4 George Washington University, Washington, DC 20052, USA; sledermann@gwu.edu \\ * Correspondence: makssie@icipe.org
}

Received: 3 January 2020; Accepted: 10 March 2020; Published: 14 March 2020

\begin{abstract}
Smallholder farmers in sub-Saharan Africa (SSA) face multifaceted and co-existing risks, such as human and animal diseases and pests. Even though smallholder farmers often experience these challenges simultaneously, interventions to address these challenges are often implemented in a piecemeal fashion. However, managing agricultural production constraints without alleviating human and livestock health burdens might not generate significant and sustained benefits to achieve the desired development outcome (e.g., reducing hunger, malnutrition, and poverty). As such, building farmers' resilience and adaptive capacity to co-existing production constraints and health burdens may require an integrated and holistic approach. Understanding the potential benefits of an integrated approach would provide critical information, for example, for revisiting the extension systems and for designing pro-poor holistically integrated interventions to tackle interrelated challenges facing smallholder farmers. In this paper, we examined the economic benefits of integrated human-plant-animal health interventions aimed at controlling malaria, stemborer infestations of crops, and trypanosomiasis, along with beekeeping as a livelihood diversification option in rural Ethiopia. We developed a whole-farm multiperiod mathematical linear programming model to examine the economic consequences of the interventions. Our results suggest that relaxing livelihoods and the human-plant-animal health constraints that farmers face has the potential to at least double income. The results further show that exploiting the potential synergies among interventions can generate higher economic benefits. The annual income from the combined interventions is $35 \%$ higher than the sum of the income gains from each intervention alone. Our results support an integrated approach to achieve holistic outcomes in areas where these development constraints co-exist.
\end{abstract}

Keywords: co-existing agricultural risks; integrated health interventions; economic benefits; multiperiod linear programming; Ethiopia

\section{Introduction}

Smallholder farmers in sub-Saharan Africa (SSA) face multifaceted and overlapping risks. For example, the simultaneous occurrence of malaria, animal diseases, pest infestations of crops, and climate change affect smallholder farmers [1-3]. As smallholders, for whom agriculture forms the basis of their livelihoods, have a limited ability to cope with risks, any shock that reduces agricultural productivity can have significant impacts on their wellbeing [4-8]. However, managing agricultural 
production constraints without alleviating human and animal health burdens might not generate significant and sustained benefits for achieving the desired development outcome (e.g., reducing hunger, malnutrition, and poverty). As such, building farmers' resilience and adaptive capacity to co-existing production constraints and health burdens may require a holistic approach. This, in turn, calls for new and integrated approaches to address multiple constraints [9-18].

In this paper, we examine the impact of introducing integrated health interventions that address the co-existing constraints of farmers in Ethiopia. These interventions include an integrated vector management (IVM) package to control malaria, biconical (Ngu) tsetse fly traps to control trypanosomiasis, and push-pull technology to address stemborer and fodder shortages. All three interventions are eco-friendly, since no pesticides are used. This, in turn, mitigates biodiversity losses and public health problems associated with excessive use and misuse of pesticides. In addition to the above three interventions, improved beekeeping was promoted to relax farmers' financial constraints by diversifying their income sources (see Section 2.2 for details of the interventions).

Malaria, trypanosomiasis, and stemborers are major productivity-limiting factors in SSA. SSA accounts for more than three-quarters of the global cases and deaths due to malaria. Malaria accounts for $40 \%$ of the public expenditure in Africa [19,20]; as a result, malaria creates a huge economic burden on the region. Furthermore, livestock productivity and draught power performance are constrained by trypanosomiasis [21-23]. Due to trypanosomiasis, nearly three million cattle die annually, resulting in a direct economic loss of 1-1.2 billion USD. It also kills more than 50,000 people annually, although the impact on humans is declining over time. Accounting for the indirect losses, SSA incurs up to 4.75 billion losses annually [22,24-27]. Similarly, stemborer pests cause losses of up to $20 \%-88 \%$ in crop production in different parts of SSA, exacerbating food insecurity in the region [28-32]. These problems are further aggravated by other biophysical and socioeconomic constraints, such as natural resource scarcity and degradation and poor access to markets [4,7-9].

Even though smallholder farmers encounter multiple constraints, development policies and agricultural interventions are often implemented in a stand-alone manner [9]. Malaria control using insecticide-treated bed-nets and dichlorodiphenyltrichloroethane (DDT) improves human capital $[33,34]$. Positive gains were also documented from trypanosomiasis control using vaccines, insecticide-treated cattle, targets and traps, release of sterile male tsetse flies, and chemicals [23,35-37]. Furthermore, controlling stemborer infestations through parasitoids and push-pull technology was found to have economically significant gains [38-40].

However, fragmented individual interventions addressing the human-plant-animal health challenges could be criticized for three reasons. Firstly, individual interventions may not be able to generate sufficient benefits to sustainably reduce poverty and food insecurity $[9-11,18,41]$. Secondly, these interventions might have a small impact, or the impacts might not last long $[9,12,42,43]$. Thirdly, implementing individual interventions with little or no coordination could be expensive, which leads to the suboptimal allocation of scarce resources [44,45].

Cognizant of the above shortcomings, a small but growing body of literature has started to investigate the potential synergies and trade-offs among interventions. In terms of increasing productivity income and reducing risks, synergies among crop technologies have been documented [46-49]. Furthermore, addressing the constraints of the poor through multi-layered interventions could bring meaningful benefits compared to single interventions $[8,12,14]$. Contrary to this literature, a few studies have empirically found that multiple interventions may not necessarily lead to higher benefits [50,51]. These groups of studies may imply that a big push through a simultaneous investment in many sectors may not be needed [52]. The debate for or against multiple interventions seems to suggest that more research is required to fine-tune interventions that benefit resource-poor farmers.

The interventions and the empirical results reported in this paper offer one of the first attempts to address the multiple constraints of smallholder farmers. To our knowledge, no empirical study has so far reported on the impacts of integrated animal-human-plant health interventions. We also 
contribute to the mixed findings of previous studies on the economic gains of multiple non-health interventions in various contexts [12,14,46-52]. The empirical results support the argument in favor of multiple interventions. Our results suggest that multiple technologies and strategies relaxing farmers' production constraints and risks bring higher benefits than single interventions. Our findings fit into the theoretical literature that argues for a big push to address the social-ecological-institutional limitations that poor people face $[10,17,18,53,54]$. Furthermore, the integrated approaches considered in this study are in line with the United Nations' Agenda 2030, which calls for a holistic approach to achieving the Sustainable Development Goals. Thus, this paper provides timely evidence of the impact of the integrated interventions on rural households facing complex constraints.

The remainder of the paper is organized as follows. Section 2 describes the study area and offers details on the individual interventions, as well as on the expected synergies among them. Section 3 presents the data together with the whole-farm multiperiod linear programming model used to examine the economic implications of individual and combined interventions. Section 4 presents our main results, while Section 5 concludes the paper and points to its implications for future interventions and policy-makers.

\section{Study Contexts and the Interventions}

\subsection{The Study Area}

The case study area, the Chora Boter district, is a semi-arid agro-climatic zone located in the Oromia Region in southwestern Ethiopia (Figure 1). In the study area, a mixed crop-livestock farming system is the dominant livelihood strategy. Even though crop production is the primary source of livelihood, livestock production plays a vital role as a source of food, cash, draft power, and manure for crop production. Maize is the most important crop, both in terms of volume of production and consumption. Peppers and chickpeas are the principal cash crops. Due to its good vegetation cover, the district is one of the high-potential areas for apiculture.

Despite the enormous potential of the district for development, crop and livestock production is constrained by pests and diseases of animals, humans, and crops. The district is highly malarious, with a prevalence rate of $1.65 \%$ [55]. Tsetse flies and food shortage hamper livestock productivity. The production and productivity of the major staple food, maize, are affected by stemborers. Socio-economic constraints, such as limited access to agricultural inputs and limited livelihood diversification options, hinder the district's development. The multiple challenges that affect the farmers of the Chora Boter district are summarized in Figure 2. Partially addressing the livestock, human, or crop production constraints alone might not bring about the expected development outcomes (e.g., improving food security) so long as the risk of contracting malaria and trypanosomiasis reduces the power of both humans and oxen, as well as the capital available for investments. 


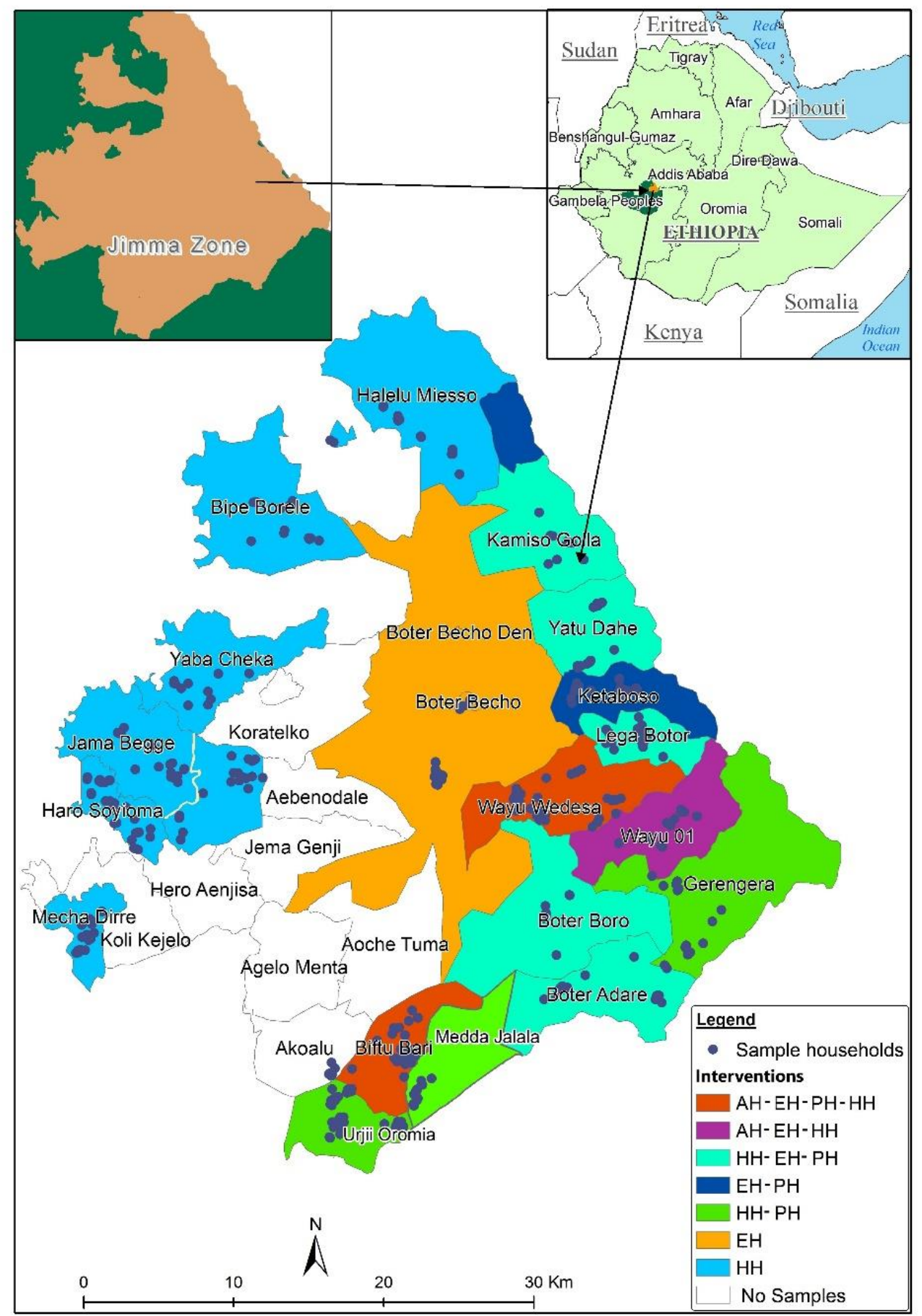

Figure 1. Study area, sample household, and intervention distribution. Note: AH, animal health; $\mathrm{EH}$, environmental health; $\mathrm{HH}$, human health; $\mathrm{PH}$, plant health. 


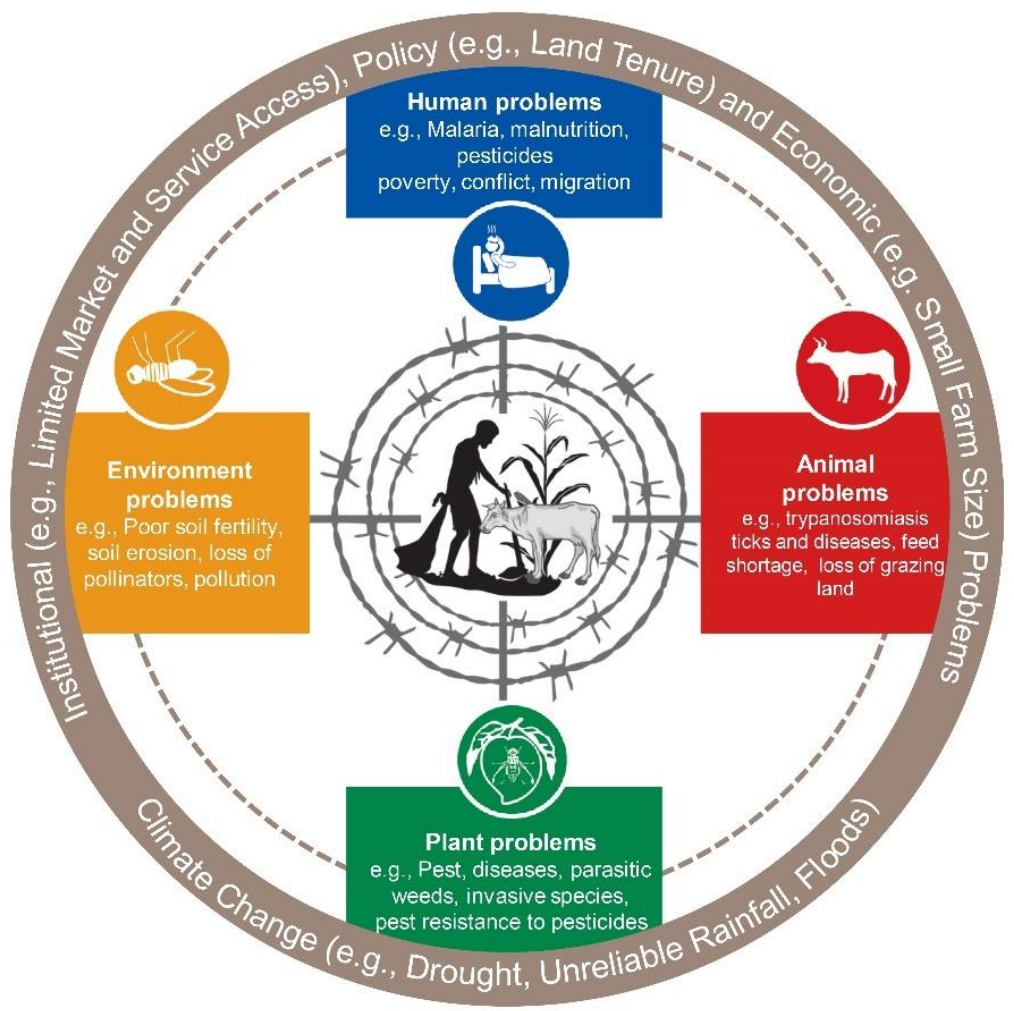

Figure 2. Set of multiple human, livestock, environmental, and crop constraints in the Chora Boter district, which require the integration of multiple interventions to be impactful.

\subsection{The Integrated Health Interventions}

Since 2005, the International Centre of Insect Physiology (icipe), the Government of Ethiopia, and donors have been piloting integrated human-animal-plant-environmental health interventions in the case study area. The interventions include: The demonstration of biconical (Ngu) traps for controlling tsetse and trypanosomiasis (animal health intervention); the Integrated Vector Management (IVM) package, including an education campaign for malaria control (human health intervention); push-pull technology for maize stemborer control (plant/crop health intervention); and improved beekeeping to generate additional income (environmental health and livelihood intervention). The animal and human health interventions are community-level interventions, while the plant and environmental health interventions are household-specific interventions. Figure 3 presents the pictorial description of the interventions. In the next sub-sections, we discuss each intervention in detail.

\subsubsection{Tsetse Fly Control}

Biconical traps were introduced to the study area in 2005 to control tsetse flies, which, in turn, works to reduce trypanosomiasis infections in livestock. A total of 2780 traps were deployed across the villages. The direct benefits of these traps include reduced medical expenditure for treating animals, as well as reduced livestock morbidity and mortality. These direct benefits translate into increased livestock productivity. Owing specifically to higher survival rates among livestock, one can expect a significant improvement in food security, mainly due to improved milk production, but also to the increased sales of livestock and livestock products. One of the indirect effects of minimizing the problem of trypanosomiasis from an area is that ox power availability for crop cultivation will increase [23]. As a result, crop production could increase. As the expenditure on livestock treatments declines, farmers may reallocate the money to other productive activities. 


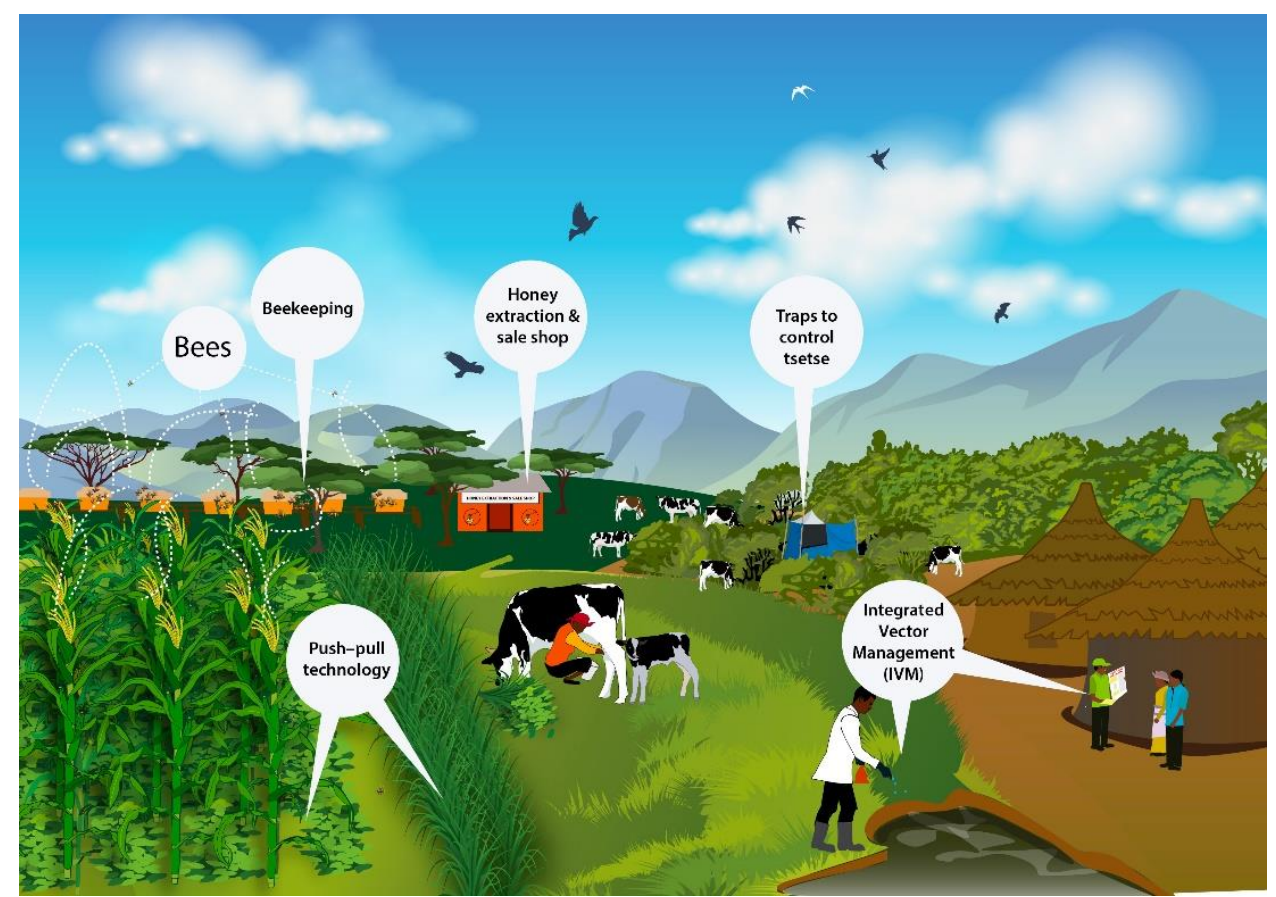

Figure 3. Human-animal-plant-environmental health interventions.

\subsubsection{Mosquito Control}

The human health intervention, which is a community-level intervention, was introduced in 2009 to control mosquitos using Integrated Vector Management (IVM). The IVM involves integrating a novel biological control (Bacillus thuringiensis israelensis (Bti)) for mosquito larvae with community education and mobilization for managing mosquito breeding sites. The IVM intervention is in line with the WHO's global targets set for vector-borne disease control [56]. Between 2009 and 2015, about 25,000 (students, community members, extension officers, and military people) were trained in malaria education. Similarly, about 3389 mosquito breeding places or places positive for mosquito larvae were treated with Bti.

The potential direct benefits of IVM include reduced household expenditure on malaria treatment and prevention. The indirect gains include increased school attendance of children and an increased amount of quality labor by reducing the number of days lost due to malaria illness, which may translate into increased farm productivity, higher incomes, and better food security. The IVM intervention is also likely to reduce the demand for insecticide sprays, which generates positive environmental benefits and reduced household expenditure on malaria-prevention tactics. Household expenditure reductions such as these can increase farmers' liquidity, which may, in turn, stimulate increased investment in capital-intensive farm technologies.

\subsubsection{Maize Stemborer Control}

Push-pull technology (PPT) was introduced in 2013 as a plant health intervention in the study area. PPT is a planting system in which maize is intercropped with a perennial fodder legume called Desmodium and a perennial fodder grass called Brachiaria [57]. While the Desmodium has the property of repelling ("push") stemborers, Brachiaria attracts pests ("pull"). These natural properties of the fodder crops effectively protect maize from stemborer damage. Desmodium also fixes nitrogen. Both fodder crops protect the soil from erosion, and also offer high-quality livestock feed. The increase in fodder biomass can increase farmers' flexibility in making crop production decisions. The decision on what crops to grow is also governed by the fodder supply of each crop, as livestock mainly depend on crop residue $[39,57]$. The potential direct benefits of adopting push-pull technology include crop yield 
gains due to reduced crop damage by stemborer infestations, increased livestock productivity and production due to high fodder production in terms of both quantity and quality, and improved soil health-all of which improve farmer households' incomes and food security levels. The indirect benefits of push-pull technology principally entail lower production costs and environmental sustainability due to a reduction in the use of agrochemicals, such as nitrogen fertilizers, pesticides, and herbicides.

\subsubsection{Improved Beekeeping}

This intervention promotes frame hives, and it is a component of an environmental health intervention. The intervention also supports the construction of a marketplace for the processing, packaging, and marketing of honey, which enhances beekeepers' capacity to produce quality honey. This intervention offers direct benefits by increasing income, and the indirect benefits include improving pollination services that bees provide and enhancing environmental conservation. As of 2016, a total of 1200 improved beehives with colonies were promoted to the local communities.

\subsubsection{Expected Synergies Between and Among the Interventions}

The individual interventions outlined above have synergetic effects, which can overcome co-existing risks that farmers are facing. Figure 4 describes the pathways for the synergies between and among the four interventions. For instance, controlling malaria has the potential to not only reduce costs for malaria treatment, but also to improve the availability of human capital for new income-earning opportunities and to intensify agricultural production. The introduction of push-pull technology, an intensification strategy itself, enables farmers to produce more maize in a smaller area. With land spared on maize, additional opportunities exist for farmers to diversify into the production of high-value crops, such as black pepper and chickpeas. In addition, avoiding the use of harmful chemicals and introducing improved beekeeping to increase pollination services can augment these synergies further.

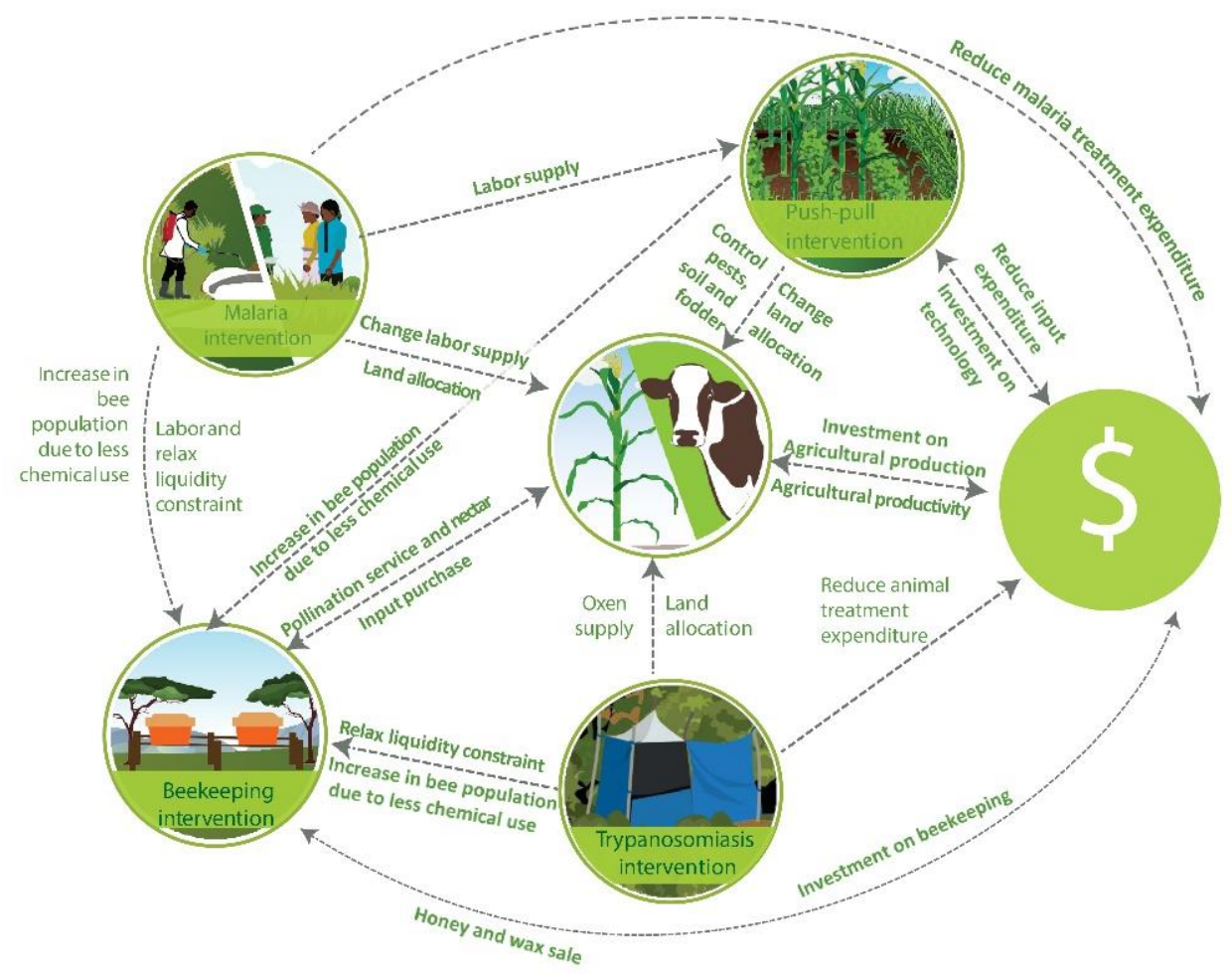

Figure 4. Expected synergies between and among interventions. 


\section{Materials and Methods}

\subsection{Data Sources}

The data for this study came from three sources. Firstly, we collected primary data using a household survey conducted in 2016. These data were collected from 544 randomly selected farm households in 19 villages of the district (see Figure 1). We used a structured questionnaire for data collection, which captured detailed information, including current crop and livestock production systems, input and output data for crop and livestock production, input and output prices in the locality, household crop and livestock product consumption data (crops, milk, butter, and honey), productive assets (labor, family size, cultivated area for each crop, and livestock), utilization of crop and livestock products, sources of livestock fodder, crop and livestock prices, crop and livestock technologies (e.g., seeds and beehives), and the land market. Information on the prevalence of malaria and trypanosomiasis, as well as on their socio-economic impacts (e.g., treatment expenditure, number of days lost due to malaria), was also collected. Secondly, we gathered additional information using focus group discussions. Data on the impact of trypanosomiasis on livestock production (prevalence and mortality rates for different livestock types, calving rate, lactation length, milk offtake, and oxen power) and malaria (prevalence rate, human labor, and treatment expenditure) were collected from focus group discussions.

Similarly, we used focus group discussions to collect data on the effect of push-pull technology on the maize yield trend, lactation length, milk yield, and labor demand for plowing, weeding, harvesting, and threshing. The data on the absconding rates and lifespans of hives were obtained from focus group discussions too, as was the average land rental value.

We obtained Desmodium and Brachiaria dry matter data from the on-farm push-pull technology experiment carried out by icipe in the study area. In addition to the above data sources, we used information from previously (un)published papers to compute fodder production [58] and livestock dry matter requirements [59].

\subsection{Empirical Methodology}

This section presents the conceptual framework, the whole-farm multiperiod linear mathematical programming model used to estimate the potential economic benefits of the interventions, and the scenarios used to evaluate these benefits.

\subsubsection{Conceptual Framework}

The conceptual framework used in this study was based on the theory of the farm household model [60]. This approach allowed us to capture the non-separability of production and consumption decisions, as farm households make joint decisions about their production, consumption, and trading, and such decisions are subject to the full income constraint. Rural input and output markets in many economies of SSA, including those of Ethiopia, are either underdeveloped or absent. Most of the household food and livestock feed consumptions, therefore, come from own-farm production. Moreover, market imperfections create transaction costs. If transaction costs are high, households find it unprofitable to either buy or sell a good - including labor —in the market, and, hence, remain autarkic [61]. With imperfect markets and the existence of farm constraints (such as labor and cash), production and consumption decisions are no longer separable, and conventional microeconomic theory (unconstrained profit-maximization framework) is no longer suitable for modeling farm households' behavior. Furthermore, the farming population of this study jointly practices both crop and livestock agriculture, and thus a non-separable household model is more suitable for modeling the farm households' production, technology, health intervention, and input use decisions. 


\subsubsection{Empirical Model}

In this paper, we used a whole-farm multiperiod linear programming (LP) model. Previous studies have used linear programming models to examine the impacts of new technological and institutional interventions [62-67]. In Ethiopia, the authors of [62] used LP to assess the ex-ante impact of introducing forage legumes and improved dairy cows into the existing farming system. The LP model was also used to evaluate trypanosomiasis control activities in south-western Ethiopia [64] and for diet optimization $[65,66]$. We opted to use a mathematical programming model in a whole-farm context because it allowed us to capture not only the complexity of smallholder farming systems in terms of resource, socio-economic, and market-related constraints, but also to simultaneously capture the feedback and interaction between and among various activities and resources. It also generates critical economic insights, including the opportunity costs (shadow prices) of scarce resources (e.g., farmland) allocated to different enterprises [7]. The selected model also allows the optimization of the multiple objectives of farmers: Maximizing income, meeting household consumption, and livestock feed requirements (food-feed first or a safety-first approach).

Based on the information obtained from farmers, researchers, and development experts, we considered an average time horizon of eight years (2016-2023) in our model. Our information from these experts indicated that push-pull technology and improved beehives have lifespans of about six and ten years, respectively, before renewed investments (resowing of perennials or replacement of beehives) need to be undertaken. The model thus allows farm households to maximize the discounted annual net income, which is the net present value (NPV), over eight years by choosing the optimal combination of crop, livestock production, and other livelihood strategies, which are subject to the constraints. Algebraically, it can be specified as follows:

$$
\operatorname{Max} Z=\sum_{j=1}^{J} \sum_{t=1}^{T}\left[\frac{R_{j t} X_{i j t}}{(1+r)^{t}}\right],(\forall j=1,2,3 \ldots, J),(\forall t=1,2,3, \ldots T),
$$

subject to

$$
\sum_{i=1}^{K} \sum_{j=1}^{J} \sum_{t=1}^{T} A_{i j t} X_{j t} \leq b_{i t}, \quad X_{j t} \geq 0,(\forall i=1,2.3 \ldots, K),
$$

where $Z$ is the NPV (value of the objective function), which provides a simultaneous solution of the combined intervention program for all of the periods considered, and $i$ refers to the $i$ th resource and constraint. Income earned in the years succeeding the first is discounted with the discount interest rate $(r)$ to reflect the time value of money. The discount interest rate, which is $18 \%$, is based on the observed interest rates in the study region [68]. The variable $R_{j t}$ is the net revenue per unit of activity $j^{t h}, X_{i j t}$ is the level of the $j^{t h}$ activity, $T$ is the number of periods, $J$ is the number of possible activities, and $K$ is the number of different resources and constraints. We considered constraints such as land, labor, cash, access to technology, access to off-farm labor markets, and access to various sources of credit. Furthermore, farmers' decisions are constrained by the need to fulfill food consumption requirements, either from their production or by purchases in the local market. The parameter $A_{i j t}$ represents the quantity of the $k^{\text {th }}$ input required to produce one unit of $j^{\text {th }}$ activity, while $b_{i t}$ is the amount of $k^{\text {th }}$ production resources available to farmers in period $t$.

\section{Model Activities}

Crop activities: The major crop activities consist of mono-cropped maize, maize intercropped with push-pull technology, sorghum, chickpeas, teff, beans, and peppers. Chickpeas are grown using residual moisture and are often rotated with maize crops. This rotation activity was considered in the model specification. Except for maize push-pull technology intercropping, data on the crop-residue yield for each crop activity were based on grain-straw conversion factors [58]. The fodder data from push-pull intercropping came from an on-farm experiment conducted by icipe. Crop by-products are 
the primary sources of livestock fodder. Table 1 summarizes the base crop yield and average price data generated from the household survey. It also indicates the base per capita consumption of such crops. On average, a household has 3.31 consumer units or adult equivalent units. The total food consumption will change over time, as the family size in a household is expected to increase annually by $2.15 \%$ [69].

Table 1. Yield, price, and consumption of major crops.

\begin{tabular}{cccc}
\hline Crop & Yield (kg/ha) & $\begin{array}{c}\text { Unit Price (Ethiopian } \\
\text { Birr-ETB/kg) }\end{array}$ & $\begin{array}{c}\text { Per Capita } \\
\text { Consumption (kg) }\end{array}$ \\
\hline Maize & 3255 & 4 & 125 \\
Sorghum & 1359 & 4 & 62 \\
Chickpeas & 941 & 13 & 30 \\
Teff & 731 & 13 & 41 \\
Black pepper & 708 & 52 & 8 \\
Beans & 848 & 6 & 20 \\
\hline
\end{tabular}

Data source: Own household survey, 2016; ETB, Ethiopian Birr (denotes local currency unit); exchange rate, 1 ETB (local currency unit) is equal to 0.044 USD.

Livestock activities: Farmers in Ethiopia maintain livestock for draft power, manure, milk, and insurance against shocks. Based on the survey data, a farm household has two cows, two oxen, one bull, one heifer, one goat, and four local and two improved beekeeping hives. For livestock production, we assumed a steady-state (stationary equilibrium) livestock investment [63]. This assumption is important in making a valid comparison of alternative intervention options. The major outputs generated from livestock activities include draft power, milk, butter, honey, wax, herd replacements, and culling. The milk production that is not used for household consumption is processed into butter. As farmers live far from the urban center where milk is in higher demand, it is difficult to sell milk every day. Based on the survey data, we incorporated productivity and price parameters for livestock and livestock products into the model.

Consumption, purchase, and sale activities: In addition to production-related activities, the model also captures consumption activities from crops and livestock, labor-hire and sale, land rentals, crop and livestock sales and purchases, and livestock product sales. Crop and livestock activities are associated with variable costs in the objective function-namely, costs for purchasing seed, fertilizer, and pesticides, hiring labor, and treatment expenditure. In this regard, cash income obtained from sales can be used to cover the expenses implied by the stated variable costs.

\section{Model Constraints}

Human and ox labor: The empirical model accounts for labor and ox power constraints for plowing, planting, weeding, harvesting, and threshing crops and for livestock keeping. Labor for crop production is in the form of both family and hired labor. Five human labor (person-days per hectare) periods of two months each were identified for crop and livestock production based on important farm operation. For ox labor (ox-days per hectare), we considered only one period (April-May) for land preparation for all crops, but for the teff crop, two oxen labor periods for land preparation and planting (June-July) and for threshing (October-November) were considered. The total available workforce in a household is expected to increase annually by $2.15 \%$ due to the growth in family size [69]. The baseline labor available is 2.60 person (man)-equivalents per household.

Household consumption constraint: The model also employs a minimum level of consumption constraints based on annual subsistence requirements for the average family size. This food-first criterion implies that the farmer only sells his/her crops and livestock products after the minimum family food requirement has been met. Therefore, consumption constraints are placed on crop and livestock production activities. The base per capita crop consumption requirements are presented in Table 1 . The base annual figures for per capita milk, butter, and honey consumption are $35 \mathrm{~L}, 3 \mathrm{~kg}$, 
and $20 \mathrm{~kg}$, respectively. The total crops and livestock products consumed at home vary from year to year as the families grows in numbers. The baseline family size is 3.63 adult equivalents.

Land: On average, a representative farm household has 2.75 hectares, including grazing land (0.75 ha). Farmland constraints are relaxed in the model through renting-in and -out of the land.

Livestock feed demand and supply: The livestock dry matter requirement is met from crop by-products and grazing land. The dry matter requirement of each animal type is computed as a function of its weight [53]. Table 2 shows livestock prices and dry matter requirements.

Table 2. Livestock type, product price, and dry matter requirement.

\begin{tabular}{ccc}
\hline Livestock Type & Unit Price (ETB per Head/kg) & Dry Matter Requirement (per Head) (kg) \\
\hline Cow & 6150 & 1597 \\
Ox & 7000 & 2281 \\
Heifer & 4500 & 1141 \\
Bull & 4150 & 1141 \\
Male/female calf & 2200 & 456 \\
Female adult goat & 1300 & 228 \\
Male adult goat & 1700 & 228 \\
Kid male/female goat & 500 & 228 \\
Culled ox & 4500 & NA \\
Culled cow & 3500 & NA \\
Culled male goat & 700 & NA \\
Culled female goat & 700 & NA \\
Butter & 133 & NA \\
\hline
\end{tabular}

Source: Household survey, 2016; ETB, Ethiopian Birr (denotes local currency unit); exchange rate, 1 ETB (Ethiopian Birr local currency) is equal to 0.044 USD; NA, not applicable.

Working capital: The capital required to finance input purchases is covered mainly from farmers' sources because access to credit in the study area is limited.

Crop and livestock balance: These constraints are included in order to ensure that grain yield from crop production will be transferred to the subsistence balance and selling equations. In addition, crop by-products (straw) from crop production are transferred to livestock production. Livestock balance restriction ensures that there is a balance between production, consumption, and marketing activities for each livestock-keeping activity.

Livestock transfer constraints: Transfer rows relate the output of one activity to another activity in the model. Replacement of animals will be made from the existing stock on the farm. Culled animals and surplus animals over a replacement will be disposed of through sales. To keep the herd structure constant, the livestock number on the right-hand side of the model is formulated as an equality (integer) constraint.

\subsubsection{Scenarios for Evaluating the Benefits of Interventions}

To examine the benefits of the different interventions, we introduced nine scenarios (Figure 5).

The baseline scenario, IP1, reflects farmers' crop and livestock production and income status in the absence of the interventions. Scenarios IP2 to IP5 represent individual intervention options, while IP6 to IP9 reflect multiple intervention options. Scenario IP2 introduces tsetse fly traps. Scenarios IP3, IP4, and IP5 refer to IVM for the malaria control, improved beekeeping, and push-pull technology interventions, respectively. Scenario IP6 considers push-pull technology and improved beekeeping interventions jointly, while scenario IP7 combines the push-pull technology, modern beekeeping, and IVM interventions, and scenario IP8 adds the trap intervention to IP6. Finally, all of the interventions are combined in scenario IP9 (traps, IVM, modern beekeeping, and push-pull technology). The model parameters for the intervention scenarios are discussed next. 


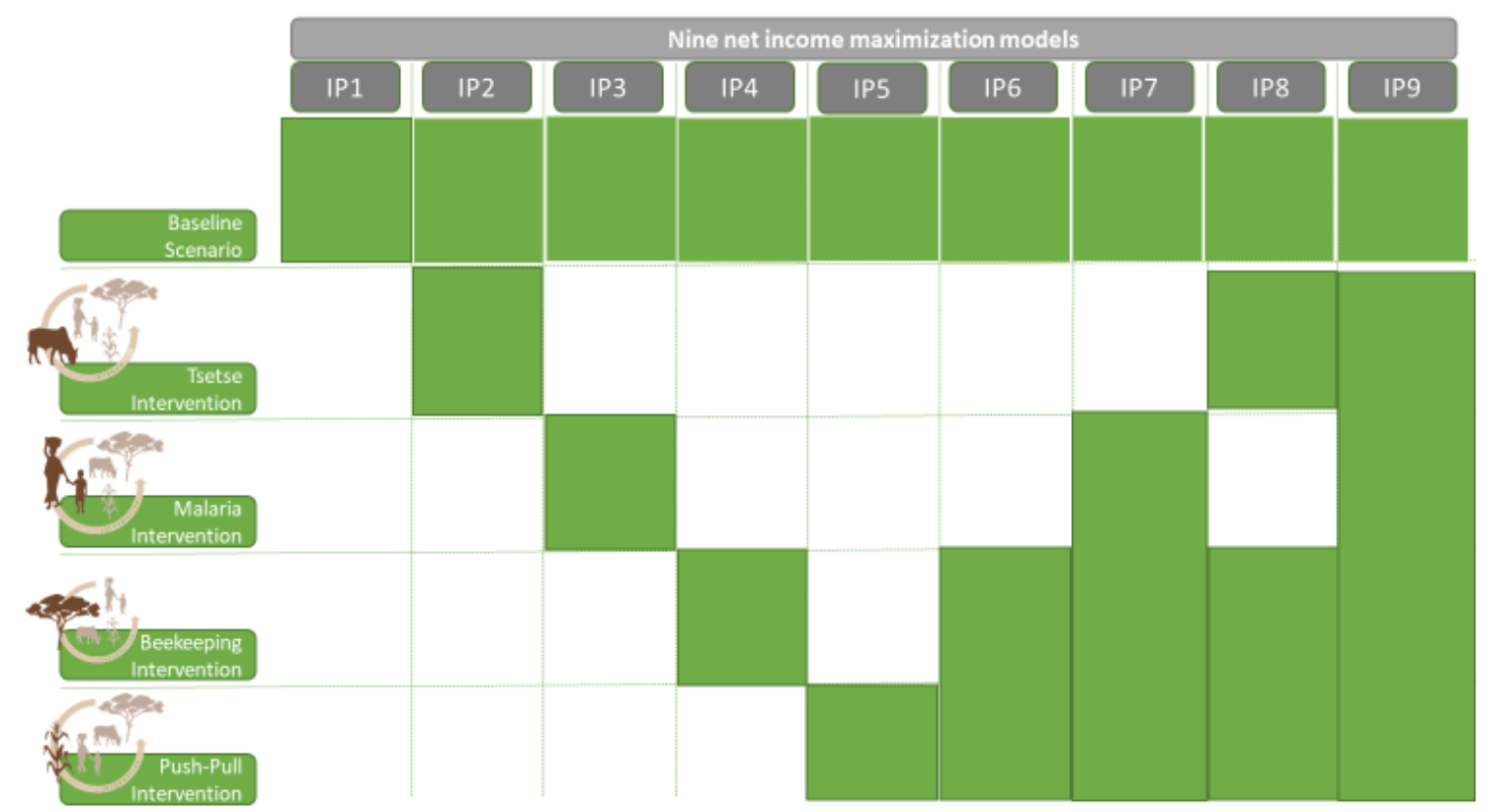

Figure 5. Model scenarios. Note: IP refers to the interventions.

For the tsetse control scenario (IP2), the prevalence of trypanosomiasis and livestock mortality rates with respect to cattle and goats is presented in Table 3. The average disease prevalence was $37 \%$ before tsetse fly control and $14 \%$ thereafter (an absolute reduction of $23 \%$ ), while mortalities decreased from $15 \%$ to $5 \%$ (Table 3). Farmers' perceptions of the current disease prevalence $(13.8 \%)$ were consistent with the estimated prevalence range of $1.38 \%-17.15 \%$ in Ethiopia [70]. Of the farmers who were aware of tsetse prevalence, $66 \%$ of the sampled farmers believed that the infestation rate of trypanosomiasis declined gradually. During the focus group discussions, farmers reported that the impact of trypanosomiasis is high on oxen, especially during planting season, when oxen become weak because of cultivation and the limited fodder availability during this season. Table 3 also shows that the calving interval was shorter by one year after the intervention, while milk production increased by $50 \%$, and expenditure on treatment declined by $70 \%$ due to the trap intervention.

Table 3. Livestock production parameters with and without tsetse control for modeling the tsetse fly trap intervention option (scenario IP2).

\begin{tabular}{|c|c|c|c|c|}
\hline \multirow[t]{2}{*}{ Stock Type/Parameter } & \multicolumn{2}{|c|}{ Without Tsetse Control } & \multicolumn{2}{|c|}{ With Tsetse Control } \\
\hline & $\begin{array}{c}\text { Disease Prevalence } \\
\text { Rate }(\%)\end{array}$ & $\begin{array}{c}\text { Animal } \\
\text { Mortality (\%) }\end{array}$ & $\begin{array}{c}\text { Disease Prevalence } \\
\text { Rate }(\%)\end{array}$ & $\begin{array}{c}\text { Animal Mortality } \\
(\%)\end{array}$ \\
\hline \multicolumn{5}{|c|}{ Cattle } \\
\hline Cows & 45 & 15 & 15 & 5 \\
\hline Oxen & 70 & 30 & 20 & 8 \\
\hline Calves & 30 & 20 & 10 & 5 \\
\hline Heifers & 10 & 2 & 4 & 0 \\
\hline Bulls & 10 & 2 & 4 & 0 \\
\hline Goats & 55 & 20 & 30 & 10 \\
\hline Average & 36.7 & 14.8 & 13.8 & 4.7 \\
\hline \multicolumn{5}{|c|}{ Production and Productivity } \\
\hline Calving interval (years) & 2 & & & \\
\hline Lactation length (months) & 6 & & & \\
\hline Milk production/cow/day $(\ell)$ & 2 & & & \\
\hline Ox power availability (\%) & 50 & & & \\
\hline Treatment expenditure (ETB) & 1000 & & & \\
\hline
\end{tabular}

Data sources: Focus group discussions and household survey, 2016; exchange rate, 1 ETB (Ethiopian local currency) is equal to 0.044 USD. 
In the malaria control scenario (IP3), before the IVM intervention, the entire family (100\%) fell ill with malaria, but after the intervention, the prevalence of the disease in the household dropped radically to $15 \%$. The household survey data reconfirmed that the overall prevalence rate was around $14 \%$, which corroborates the $15 \%$ obtained from the focus group discussions. This result has implications for farm labor availability (see Table 4), which climbed from $50 \%$ to $90 \%$ after the intervention. Expenditure on malaria also fell sharply after the intervention, namely, from 4750 to 453 ETB. This in line with the drop in malaria prevalence.

Table 4. Parameters for modeling the malaria intervention option (scenario IP3).

\begin{tabular}{lcc}
\hline \multicolumn{1}{c}{ Parameter } & With Malaria & Without Malaria \\
\hline Prevalence rate (\%) & 100 & 15 \\
Treatment expenditure (Ethiopian Birr, ETB) & 4750 & 453 \\
Agricultural labor available (\%) & 50 & 90 \\
\hline
\end{tabular}

Data sources: Focus group discussions and household survey, 2016; exchange rate, 1 ETB (Ethiopian local currency) is equal to $0.044 \mathrm{USD}$.

In the maize stemborer control and fodder production scenario (IP4), $40 \%$ of the sample households were aware of push-pull technology, and $21 \%$ of the sample households reported that they use the technology on their maize plot. The Desmodium and Brachiaria fodder production data were obtained from the on-farm experimental data. Farmers were unable to determine fodder production because of the frequent harvest of fodders to avoid competition with maize and also to provide feed to livestock. Table 5 reveals that the use of push-pull technology affected crop and livestock production parameters and farm labor demand. The on-farm experimental data obtained by icipe show that push-pull technology plots had stemborer infestation rates of $4.8 \%$ and crop damage rates of $0.75 \%$, while infestation rates for the mono-crop maize plots were $8.2 \%$ and for crop damage rates were $1.8 \%$. The milk yield reported by farmers is consistent with the milk production data reported in Kenya and Ethiopia, where milk production increased by $74 \%$ and $92 \%$, respectively, due to high-fodder-quality production from push-pull maize plots $[39,71]$.

Table 5. Parameters for modeling the push-pull technology intervention option (scenario IP4).

\begin{tabular}{|c|c|c|}
\hline Parameter & \multicolumn{2}{|c|}{ Parameter Value } \\
\hline Maize yield (\% from baseline yield) & \multicolumn{2}{|c|}{$\begin{array}{c}\text { Year } 1=10 \% \text { increase } \\
\text { Year } 2 \text { and above }=15 \% \text { increase }\end{array}$} \\
\hline Desmodium dry matter (tons/ha) & \multicolumn{2}{|c|}{3.6 tons/ha } \\
\hline Brachiaria dry matter (tons/ha) & \multicolumn{2}{|c|}{6.4 tons/ha } \\
\hline $\begin{array}{l}\text { Labor Demand for Maize } \\
\text { Production (Person-Days/ha) }\end{array}$ & $\begin{array}{c}\text { Non-Push-Pull Technology } \\
\text { Maize Plot }\end{array}$ & $\begin{array}{c}\text { Push-Pull Technology } \\
\text { Maize Plot }\end{array}$ \\
\hline Plowing and planting & 26 & Year $1=26$, Year $2=10$ \\
\hline Weeding & 26 & Year $1=16$, Year $2=8$ \\
\hline Harvesting and threshing & 22 & 34 \\
\hline \multicolumn{3}{|c|}{ Livestock Productivity } \\
\hline Lactation length (months) & 6 & 8 \\
\hline Milk yield per cow per day $(\ell)$ & 2 & 5 \\
\hline
\end{tabular}

Data sources: Focus group discussions, 2016, and on-farm field experiments.

In the beekeeping scenario (IP5), improved beehives achieved a $68 \%$ higher honey yield on average (at $27 \mathrm{~kg}$ per beehive per year; see Table 6). Since improved beehives-in combination with the use of a honey extractor from the established marketplace-also improved the quality of the honey produced, this brought a $54 \%$ price premium in the local market (at $94 \mathrm{ETB} / \mathrm{kg}$ ). The additional parameters used for the improved beekeeping model are presented in Table 6. 
Table 6. Parameters for modeling the improved beekeeping intervention option (scenario IP5).

\begin{tabular}{lcc}
\hline \multicolumn{1}{c}{ Parameter } & Traditional Beehives & Improved Beehives \\
\hline Honey (kg per beehive per year) & 16 & 27 \\
Wax (kg per beehive per year) & 1.5 & $\mathrm{NA}$ \\
Lifespan (years) & 3 & 10 \\
Abscondment rate $(\%)$ & 10 & 5 \\
Honey price (ETB/kg) & 61 & 94 \\
Wax price (ETB/kg) & 250 & $\mathrm{NA}$ \\
Beehive price with colony (ETB) & 900 & 1435 \\
\hline
\end{tabular}

Data sources: Household survey and focus group discussions, 2016; exchange rate, 1 ETB (Ethiopian local currency) is equal to 0.044 USD. Note: Farmers used $0.5 \mathrm{~kg}$ wax per improved beehive, which was below the recommended rate of $1 \mathrm{~kg}$ per beehive, contributing to their lower productivity.

\section{Results and Discussions}

We estimated the whole-farm multiperiod linear programming model using the General Algebraic Modeling System (GAMS) software. The structure of the multiperiod linear mathematical programming model and the detailed activities and constraints, along with the parameter values or data, are provided as supplementary online materials.

\subsection{Estimated Economic Benefits of the Interventions}

Figure 6 presents the discounted net returns from the use of the different interventions, individually or in combination, over eight years. In Table 7 , we report the annual household income and resultant per capita yearly income associated with various intervention options. Introducing the livelihood and health interventions, individually or in combination, substantially increases discounted net income in comparison to the baseline scenario.

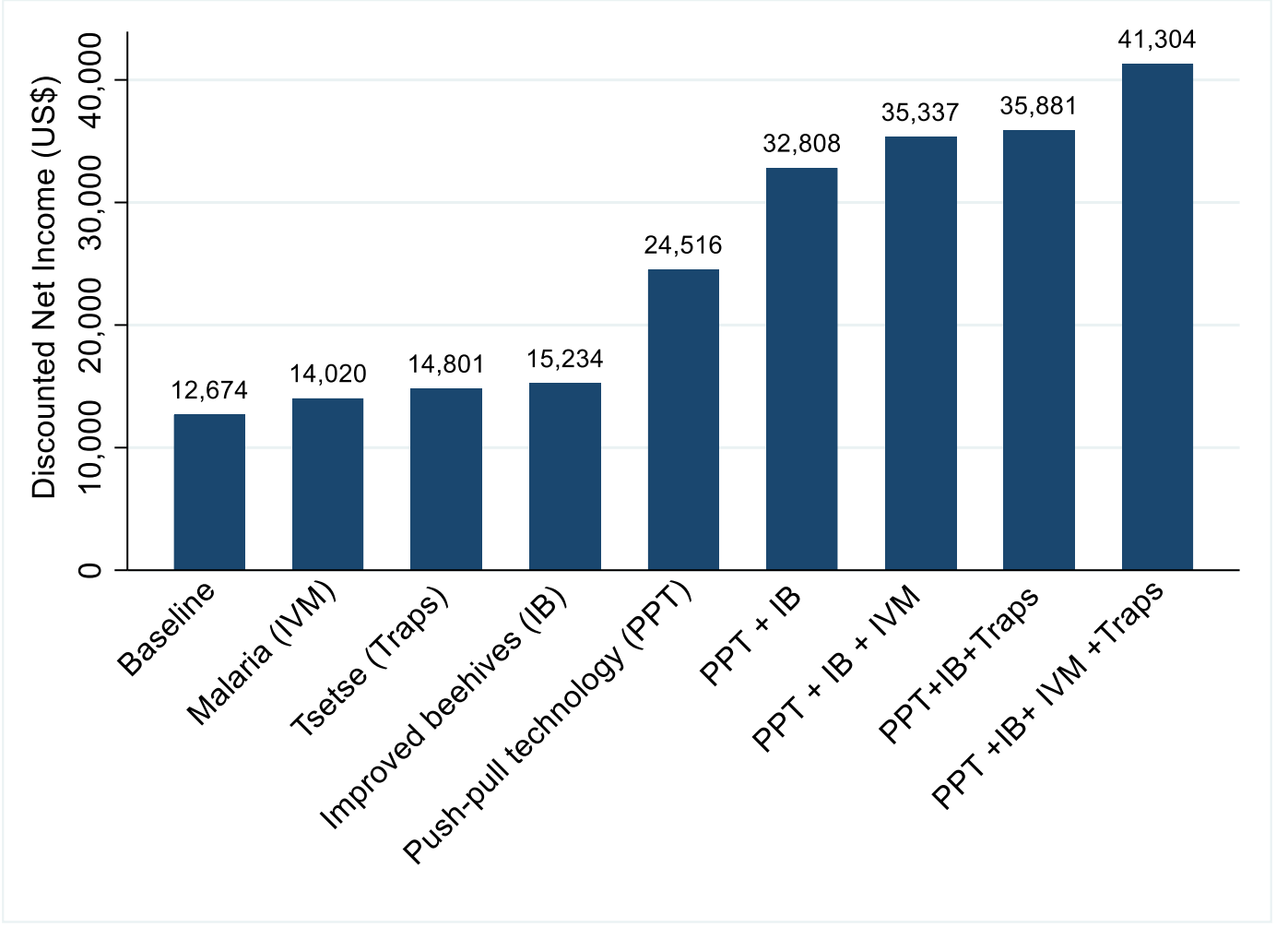

Figure 6. Total discounted net income (USD) over eight years. 
Table 7. Annual and per capita returns from individual and combined interventions (USD).

\begin{tabular}{lcc}
\hline \multicolumn{1}{c}{ Intervention Options } & Annual Income & Per Capita Income \\
\hline Baseline model & 1584 & 436 \\
Integrated vector management (IVM) package intervention for malaria & 1753 & 498 \\
Trap intervention for trypanosomiasis & 1850 & 510 \\
Push-pull technology intervention for stemborer infestations & 3065 & 844 \\
Improved beekeeping intervention & 1904 & 525 \\
Push-pull technology + improved beekeeping interventions & 4101 & 1130 \\
Push-pull technology + improved beekeeping + IVM intervention & 4417 & 1217 \\
Push-pull technology + improved beekeeping + trap intervention & 4485 & 1236 \\
Push-pull technology + improved beekeeping + IVM + trap intervention & 5163 & 1422 \\
\hline
\end{tabular}

Among the individual interventions, push-pull technology has the highest return. The high return for push-pull technology may be due to three combined effects: Higher maize yield, milk production, and biomass feed production, which can increase farmers' flexibility to switch to high-value crops (e.g., red peppers, chickpeas); improvements in other livestock production parameters (e.g., the calving rate); and land sparing, allowing diversification into high-value crops (e.g., red peppers, chickpeas). The positive income contribution of each intervention is in line with previous studies. Evidence from six East African countries shows a substantial economic gain ( 2.5 billion USD) by eliminating trypanosomiasis [22,72]. Furthermore, a 39\% increase in net maize income from push-pull technology adoption was reported in Kenya [39]. In Ethiopia, the authors of [62] found a 74\% increase in net income due to the introduction of legume fodders into the cereal farming systems.

While the impact of each individual intervention is remarkable, much higher returns are observed when the interventions are combined. For instance, the income gains double when improved beehives are combined with push-pull technology. As we combine push-pull technology with each intervention, the additional gain in net income increases considerably. However, it seems that the marginal contribution of the trypanosomiasis intervention (traps), together with push-pull technology and improved beekeeping, is relatively small. This might indicate that the full effects of the traps are only observed when the human sides of the constraints are addressed (malaria). This argument seems to work, as the income gains become substantially larger when all of the co-existing constraints are relaxed. The results clearly show that more significant benefits can be generated by exploiting the potential synergies that exist between and among the different interventions, because the additional annual income due to the integration of the combined interventions was 35\% (368 USD per capita per year), higher than the sum of the income gains from each intervention (see Figure 7). These results are in agreement with the existing literature, which found higher and more significant positive effects with the integration of technologies compared to individual interventions [7,8,12,14,46,49]. For instance, the authors of [49] found that mango productivity and the income of farmers increase substantially ( $6 \%-95 \%$ for mango productivity and $9 \%-137 \%$ for mango income) as the number of integrated pest management strategies in the same plot increases. Evidence from Ethiopia shows that the adoption of three crop technologies or practices (cropping system diversification, conservation tillage, and improved maize varieties) increases net maize income by $137 \%$, as compared to the adoption of a single technology or practice [46]. 


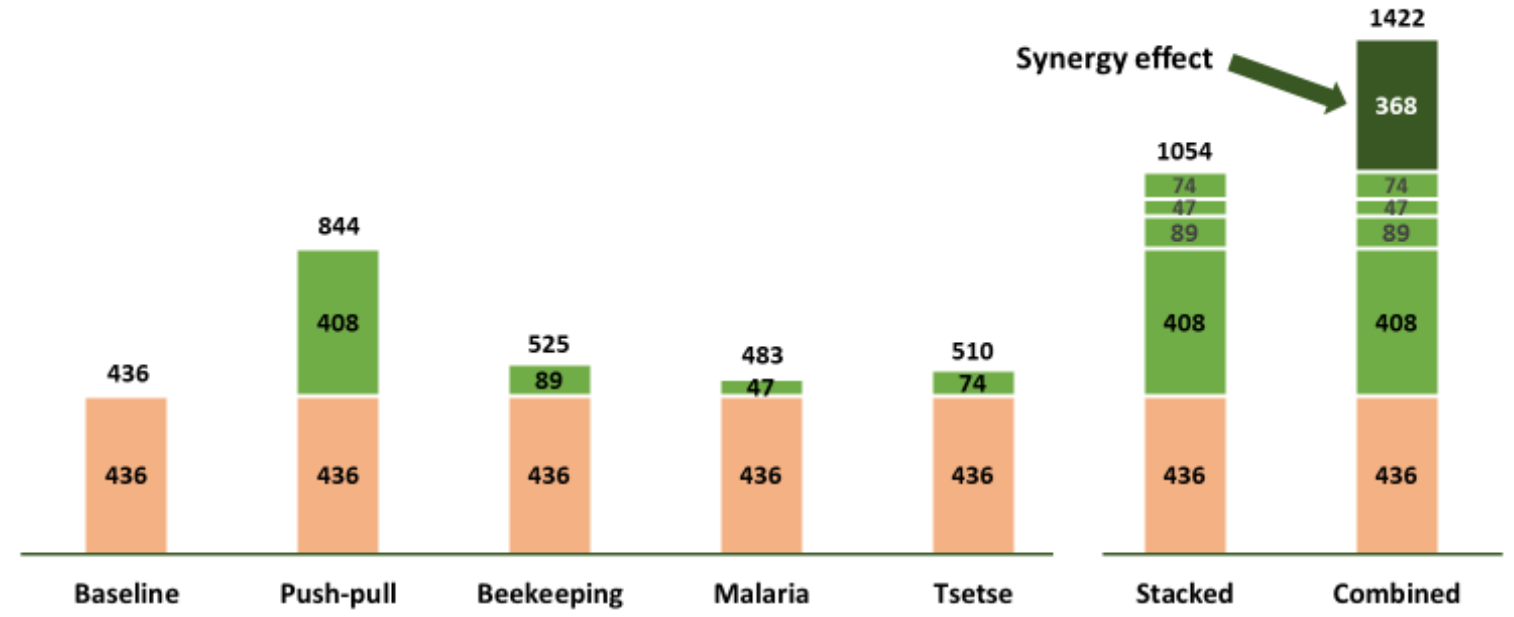

Figure 7. Additional income gains due to integration (USD per person per year). Note: (1) The values for the stacked intervention were calculated by comparing the gains from the combined interventions to the four stacked interventions, assuming these interventions were implemented separately (i.e., income gains from push-pull technology, integrated vector management (IVM), traps, and improved beekeeping were compared with the income obtained from the baseline). The difference between the two is the synergy effect identified. (2) The light brown color in the bar graph indicates the baseline per capita per year value; green indicates the additional income generated from each intervention compared to the baseline value, and the dark green represents the size of additional income gains mainly due to integration (i.e., the synergy effect).

\subsection{Impacts on Land Productivity}

In addition to income benefits, we also report the benefits of the interventions on resource value. That is, how improved livelihood and integrated health interventions might alter the values of critical resources such as land. We show this benefit using the estimated marginal value productivity (MVP), reported in Figure 8 [62]. The MVP is positive in all scenarios. For example, the marginal value of land increased from 389 to 878 USD for the PPT intervention in scenario IP5 compared with IP1, the baseline scenario. Analogously to the economic returns, land productivity was also the highest in scenario IP9, where all of the interventions were combined. In the Ethiopian Highland, the authors of [62] reported an increase in land value by $74 \%-165 \%$ as a result of the introduction of improved fodder and dairy cows into the existing farming system of the Ethiopian Highland.

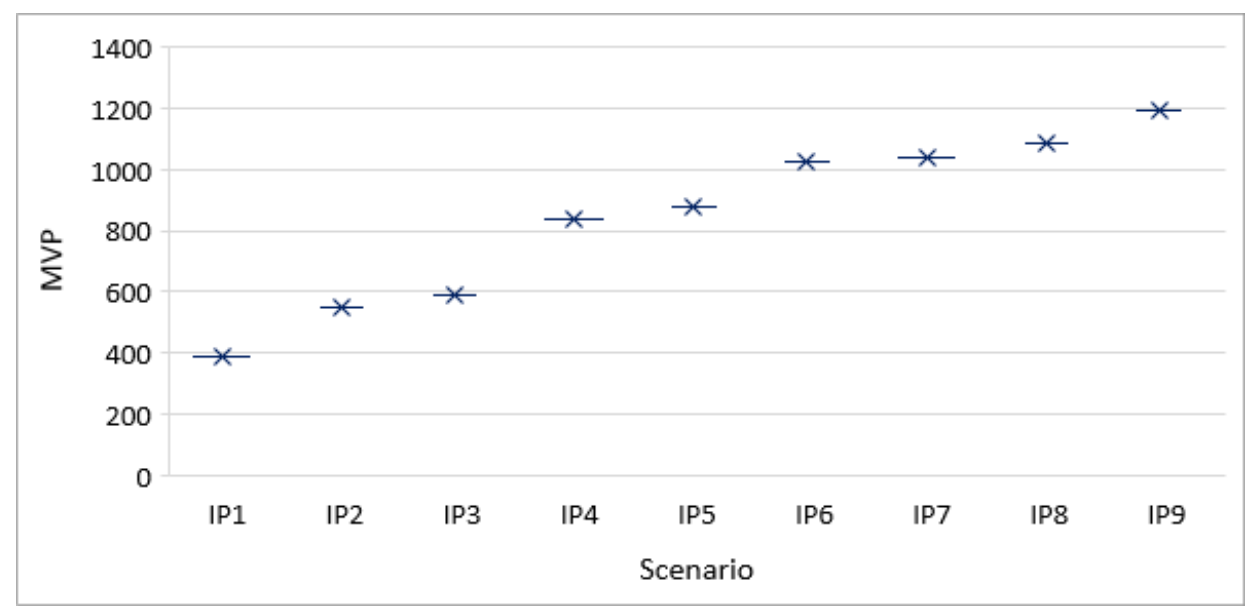

Figure 8. Marginal value productivity (MVP) of land under different scenarios (USD). 


\section{Conclusions and Policy Implications}

In this article, we provided evidence of the economic return of introducing multiple health interventions, which cut across animals, humans, and crops, into the existing farming systems in Ethiopia. We used a multiperiod linear mathematical programming technique in a whole-farm context. The approach we used enabled us to optimize farmers' multiple objectives, including maximizing income, meeting household consumption, and livestock feed requirements. The interventions and the empirical results reported in this paper offers one of the first attempts to address multiple constraints of smallholder farmers simultaneously. The study provides the first empirical results on the impacts of integrated animal-human-plant health interventions. We also contribute to the mixed findings of previous studies on the economic gains of multiple non-health interventions undertaken in various farming systems.

Our findings indicate that significant income and resource productivity gains could be obtained from integrated animal-human-plant health interventions. Our study confirms that the simultaneous dissemination of integrated health interventions generates an income of 368 USD per capita higher than individual interventions. Furthermore, we documented that the income gains from multiple interventions are moderated partly through better resource-use efficiency and land productivity. Our results can contribute to building the evidence base for multiple interventions, which can provide valuable insight to policy-makers and development partners, for example, to revisit the extension system and to develop integrated interventions aligned with the Sustainable Development Goals to simultaneously tackle the numerous challenges facing smallholder farmers. However, the successful implementation of an integrated approach requires the cross-sectional coordination and building capacity of farmers, because to use more than one intervention can demand extra resources, which are often constraints for smallholder farmers.

While our study has demonstrated some interesting positive impacts of health interventions, the findings of this study may need to be interpreted with caution. First, the data for the estimation came from focus group discussions and cross-sectional household survey data, since baseline data were not collected. Additional evaluations using a well-designed experiment would allow a deeper understanding of the economics of integrated health approaches. Second, the model did not include risk and uncertainty explicitly, although household food consumption and livestock feed requirements were captured in the model. Third, the full benefits of the interventions have not yet been captured due to data limitations, which may underestimate their impacts. For instance, controlling tsetse flies and trypanosomiasis may improve livestock meat productivity. The interventions also have environmental benefits, but these benefits were not considered. Fourth, given that the case study was conducted in one district, there might be problems with inferences to the country level. Fifth, our model, like many other conventional representative farm models, fails to capture heterogeneity and interactions. Thus, bottom-up modeling approaches such as multi-agent systems could provide further insights for improved resource allocation and targeting by capturing heterogeneity and the complex interlinkages between the different production options, resource endowments, and heterogeneous responses to proposed policy interventions $[1,2,7,8]$. A final caveat is that, although we demonstrated the income gains of multiple interventions, we did not examine their relative cost-effectiveness due to a lack of accurate cost data. However, investigating the costs needed to achieve the income gains associated with each intervention, either individually or jointly, is critical for drawing a more robust recommendation on the allocation of scarce public resources [72]. Future research that aims to assess and compare the relative cost-effectiveness of individual and integrated interventions is thus crucial.

Regardless of these limitations, this case study provides valuable insights into how integrated health interventions can have a substantial positive effect on improving farm households' incomes. Development practitioners need to be encouraged to break through and link across the silos within their organizations. Embracing complexities instead of stand-alone silver bullets can support such endeavors toward identifying more synergistic interventions. 
Author Contributions: M.K.: Conceptualization, data curation, formal analysis, funding acquisition, investigation, methodology, visualization, writing—original draft. Z.A.: Literature review, Resources, visualization, writing—review and editing. T.W.: Visualization, writing—review and editing. S.T.L.: Visualization, writing一review and editing. G.D.: Visualization, writing-review and editing. S.B.: Project administration, investigation, resources. L.B.: Project administration, investigation, resources. All authors have read and agreed to the published version of the manuscript.

Funding: This work was supported by co-funding from the Biovision Foundation, Switzerland, and core financial assistance to the International Centre of Insect Physiology and Ecology (icipe) provided by UK's Department for International Development (DFID), the Swedish International Development Cooperation Agency (Sida), the Swiss Agency for Development and Cooperation (SDC), the German Federal Ministry for Economic Cooperation and Development (BMZ), and the Kenyan and Ethiopian Governments. We also thank Yohannis Mulu Tessema for his support at the initial stage of formulating the model, the enumerators and supervisors for their dedication in the field, the farmers for their time, and Emily Kimathi for developing the map. The views expressed herein do not necessarily reflect the official opinions of the donors or icipe.

Conflicts of Interest: The authors declare no conflict of interest.

\section{References}

1. Berger, T.; Troost, C. Agent-based modelling of climate Adaptation and mitigation options in agriculture. J. Agric. Econ. 2014, 65, 323-348. [CrossRef]

2. Antle, J.M.; Stoorvogel, J.J.; Valdivia, R.O. New parsimonious simulation methods and tools to assess future food and environmental security of farm populations. Philos. Trans. R. Soc. B Biol. Sci. 2014, 369, 20120280. [CrossRef] [PubMed]

3. Alliance for a Green Revolution in Africa. AGRA Africa Agriculture Report: Climate Change and Smallholder Farmers in Sub-Saharan Africa; Alliance for a Green Revolution in Africa: Nairobi, Kenya, 2014.

4. Harvey, C.A.; Rakotobe, Z.L.; Rao, N.S.; Dave, R.; Razafimahatratra, H.; Rabarijohn, R.H.; Rajaofara, H.; MacKinnon, J.L. Extreme vulnerability of smallholder farmers to agricultural risks and climate change in Madagascar. Philos. Trans. R. Soc. B Biol. Sci. 2014, 369, 20130089. [CrossRef] [PubMed]

5. McDowell, J.Z.; Hess, J.J. Accessing adaptation: Multiple stressors on livelihoods in the Bolivian highlands under a changing climate. Glob. Environ. Chang. 2012, 22, 342-352. [CrossRef]

6. Hertel, T.W.; Rosch, S.D. Climate change, agriculture, and poverty. Appl. Econ. Perspect. Policy 2010, 32, 355-385. [CrossRef]

7. Berger, T.; Troost, C.; Wossen, T.; Latynskiy, E.; Tesfaye, K.; Gbegbelegbe, S. Can smallholder farmers adapt to climate variability, and how effective are policy interventions? Agent-based simulation results for Ethiopia. Agric. Econ. (UK) 2017, 48, 693-706. [CrossRef]

8. Wossen, T.; Berger, T.; Haile, M.G.; Troost, C. Impacts of climate variability and food price volatility on household income and food security of farm households in East and West Africa. Agric. Syst. 2018, 163, 7-15. [CrossRef]

9. van Ginkel, M.; Sayer, J.; Sinclair, F.; Aw-Hassan, A.; Bossio, D.; Craufurd, P.; El Mourid, M.; Haddad, N.; Hoisington, D.; Johnson, N.; et al. An integrated agro-ecosystem and livelihood systems approach for the poor and vulnerable in dry areas. Food Secur. 2013, 5, 751-767. [CrossRef]

10. Haider, L.J.; Boonstra, W.J.; Peterson, G.D.; Schlüter, M. Traps and Sustainable Development in Rural Areas: A Review. World Dev. 2018, 101, 311-321. [CrossRef]

11. Enfors, E. Social-ecological traps and transformations in dryland agro-ecosystems: Using water system innovations to change the trajectory of development. Glob. Environ. Chang. 2013, 23, 51-60. [CrossRef]

12. Banerjee, A.; Duflo, E.; Goldberg, N.; Karlan, D.; Osei, R.; Parienté, W.; Shapiro, J.; Thuysbaert, B.; Udry, C. A multifaceted program causes lasting progress for the very poor: Evidence from six countries. Science 2015, 348, 1260799. [CrossRef] [PubMed]

13. Sachs, J. The End of Poverty: Economic Possibilities for Our Time; Penguin Books: New York, NY, USA, 2005.

14. Bandiera, O.; Burgess, R.; Das, N.; Gulesci, S.; Rasul, I.; Sulaiman, M. Labor Markets and Poverty in Village Economies. Q. J. Econ. 2017, 132, 811-870. [CrossRef]

15. Alkire, S.; Santos, M.E. Measuring acute poverty in the developing world: Robustness and scope of the Multidimensional Poverty Index. World Dev. 2014, 59, 251-274. [CrossRef]

16. Maru, Y.T.; Fletcher, C.S.; Chewings, V.H. A synthesis of current approaches to traps is useful but needs rethinking for indigenous disadvantage and poverty research. Ecol. Soc. 2012, 17, 324-338. [CrossRef] 
17. Lade, S.J.; Haider, L.J.; Engström, G.; Schlüter, M. Resilience offers escape from trapped thinking on poverty alleviation. Sci. Adv. 2017, 3, e1603043. [CrossRef] [PubMed]

18. Barrett, C.B.; Swallow, B.M. Fractal poverty traps. World Dev. 2006, 34, 1-15. [CrossRef]

19. WHO. WHO Global Malaria Programme. In World Malaria Report 2015; World Health Organisation: Geneva, Switzerland, 2015.

20. Asenso-Okyere, K.; Asante, F.A.; Tarekegn, J.; Andam, K.S. A review of the economic impact of malaria in agricultural development. Agric. Econ. 2011, 42, 293-304. [CrossRef]

21. Alsan, M. The Effect of the TseTse Fly on African Development. Am. Econ. Rev. 2015, 105, 382-410. [CrossRef]

22. Shaw, A.P.M.; Cecchi, G.; Wintd, G.R.W.; Mattiolie, R.C.; Robinson, T.P. Mapping the economic benefits to livestock keepers from intervening against bovine trypanosomosis in Eastern Africa. Prev. Vet. Med. 2014, 113, 197-210. [CrossRef]

23. Swallow, B.M. Impact of trypanosomiasis on African agriculture. In PAAT Technical and Scientific Series 2; Food and Agriculture Organization: Rome, Italy, 2000.

24. FAO. The Disease. Programme Against African Trypanosomosis (PAAT). Food and Agriculture Organization of the United Nations (FAO). Available online: http://www.fao.org/paat/the-programme/the-disease/en/ (accessed on 8 April 2019).

25. Barrett, J.C. Economic issues in trypanosomiasis control. In NRI Bulletin 75; Natural Resources Institute Chatham: Chatham, UK, 1997.

26. Cecchi, G.; Mattioli, R.C. Global Geospatial Datasets for African Trypanosomiasis Management: A Review; United Nations Food and Agriculure Organization (FAO): Rome, Italy, 2009.

27. Kabayo, J.P. Aiming to eliminate tsetse from Africa. Trends Parasitol. 2002, 18, 473-475. [CrossRef]

28. Shiferaw, B.; Prasanna, B.M.; Hellin, J.; Bänziger, M. Crops that feed the world 6. Past successes and future challenges to the role played by maize in global food security. Food Secur. 2011, 3, 307-327. [CrossRef]

29. Prasanna, B. Maize in the developing world: Trends, challenges and opportunities. In Proceedings of the International Maize Conference, Nanning, China, 12-18 October 2015; Volume 5, pp. 26-38.

30. De Groote, H. Maize yield losses from stemborers in Kenya. Insect Sci. Appl. 2002, 22, 89-96. [CrossRef]

31. Samuel, A.O.; Tabbassum, B.; Sharif, M.N.; Bhatti, M.U.; Nasir, I.A.; Husnain, T. A lag in the advancement of biotechnology: Reliable control of maize stem borers in Africa. J. Plant Prot. Res. 2018, 58, 8-24.

32. Kfir, R.; Overholt, W.A.; Khan, Z.R.; Polaszek, A. Biology and management of economically important Lepidopteran cereal stem borers in Africa. Annu. Rev. Entomol. 2002, 47, 701-731. [CrossRef] [PubMed]

33. Barofsky, J.; Anekwe, T.D.; Chase, C. Malaria eradication and economic outcomes in sub-Saharan Africa: Evidence from Uganda. J. Health Econ. 2015, 44, 118-136. [CrossRef] [PubMed]

34. Lucas, A.M. Malaria eradication and educational attainment: Evidence from paraguay and sri lanka. Am. Econ. J. Appl. Econ. 2010, 2, 46-71. [CrossRef]

35. Shaw, R.; Witt, A.; Cock, M.; Pollard, K.; Thomas, S.; Romney, D. Safeguarding the environment, food security and livelihoods from invasive species using biological controls. In CABI Study Brief 4; CABI: Wallingford, UK, 2014.

36. Kipkoech, K.A.; Schulthess, F.; Yabann, W.K.; Maritim, H.K.; Erick, M.; Mithöfer, D. The economic value of releasing parasitoid for the control of maize stemborers in East and Southern Africa. In Proceedings of the International Association of Agricultural Economists (IAAE) Conference, Beijing, China, 16-22 August 2009.

37. Kristjanson, P.M.; Swallow, B.M.; Rowlands, G.J.; Kruska, R.L.; de Leeuw, P.N. Measuring the costs of African animal trypanosomosis, the potential benefits of control and returns to research. Agric. Syst. 1999, 59, 79-98. [CrossRef]

38. De Groote, H.; Wangare, L.; Kanampiu, F.; Odendo, M.; Diallo, A.; Karaya, H.; Friesen, D. The potential of a herbicide resistant maize technology for Striga control in Africa. Agric. Syst. 2008, 97, 83-94. [CrossRef]

39. Kassie, M.; Stage, J.; Diiro, G.; Muriithi, B.; Muricho, G.; Ledermann, S.T.; Pittchar, J.; Midega, C.; Zeyaur, K. Push-pull farming system in Kenya: Implications for economic and social welfare. Land Use Policy 2018, 77, 186-198. [CrossRef]

40. Soul-kifouly, G.M.; Affognon, H.D.; Macharia, I.; Ong'amo, G.; Abonyo, E.; Ogola, G.; De Groote, H.; LeRu, B. Assessing the long-term welfare effects of the biological control of cereal stemborer pests in East and Southern Africa: Evidence from Kenya, Mozambique and Zambia. Agric. Ecosyst. Environ. 2016, 230, 10-23. [CrossRef] 
41. Twomlow, S.; Shiferaw, B.; Cooper, P.; Keatinge, J.D.H. Integrating genetics and natural resource management for technology targeting and greater impact of agricultural research in the semi-arid tropics. Exp. Agric. 2008, 44, 235-256. [CrossRef]

42. Giller, K.E.; Witter, E.; Corbeels, M.; Tittonell, P. Field Crops Research Conservation agriculture and smallholder farming in Africa: The heretics' view. Field Crop. Res. 2009, 114, 23-34. [CrossRef]

43. Kiptot, E.; Hebinck, P.; Franzel, S.; Richards, P. Adopters, testers or pseudo-adopters? Dynamics of the use of improved tree fallows by farmers in western Kenya. Agric. Syst. 2007, 94, 509-519. [CrossRef]

44. Glăvan, B. Coordination Economics, poverty traps, and the market process: A New Case Ind. Policy? Indep. Rev. 2008, 13, 225-243.

45. Rodríguez-Clare, A. Coordination failures, clusters, and microeconomic interventions. Economía 2005, 6, 1-42. [CrossRef]

46. Teklewold, H.; Kassie, M.; Shiferaw, B.; Köhlin, G. Cropping system diversification, conservation tillage and modern seed adoption in Ethiopia: Impacts on household income, agrochemical use and demand for labor. Ecol. Econ. 2013, 93, 85-93. [CrossRef]

47. Kassie, M.; Teklewold, H.; Marenya, P.; Jaleta, M.; Erenstein, O. Production risks and food security under alternative technology choices in Malawi: Application of a multinomial endogenous switching regression. J. Agric. Econ. 2015, 66, 640-659. [CrossRef]

48. Wainaina, P.; Tongruksawattana, S.; Qaim, M. Tradeoffs and complementarities in the adoption of improved seeds, fertilizer, and natural resource management technologies in Kenya. Agric. Econ. 2016, 47, 351-362. [CrossRef]

49. Soul-kifouly, G.M.; Kassie, M.; Muriithi, B.; Diiro, G.; Ekesi, S. Do Farmers and the Environment Benefit from Adopting Integrated Pest Management Practices? Evidence from Kenya. J. Agric. Econ. 2019, 70, 452-470. [CrossRef]

50. Manda, J.; Alene, A.D.; Gardebroek, C.; Kassie, M.; Tembo, G. Adoption and impacts of sustainable agricultural practices on maize yields and incomes: Evidence from Rural Zambia. J. Agric. Econ. 2016, 67, 130-153. [CrossRef]

51. Banerjee, A.V.; Karlan, D.; Osei, R.D.; Trachtman, H.; Udry, C. Unpacking a multi-faceted program to build sustainable income for the very poor. In NBER Working Paper No. 24271; National Bureau of Economic Research: Cambridge, MA, USA, 2018.

52. Easterly, W. Reliving the 1950s: The big push, poverty traps, and takeoffs in economic development. J. Econ. Growth 2006, 11, 289-318. [CrossRef]

53. Barrett, C.B.; Constas, M.A. Toward a theory of resilience for international development applications. Proc. Natl. Acad. Sci. USA 2014, 111, 14625-14630. [CrossRef] [PubMed]

54. Barrett, C.B.; Bevis, L.E.M. The self-reinforcing feedback between low soil fertility and chronic poverty. Nat. Geosci. 2015, 8, 907-912. [CrossRef]

55. Asale, A.; Kussa, D.; Girma, M.; Mbogo, C.; Mutero, C.M. Community based integrated vector management for malaria control: Lessons from three years' experience (2016-2018) in Botor-Tolay district, southwestern Ethiopia. BMC Public Health 2019, 19, 1318. [CrossRef] [PubMed]

56. WHO. A Tool Kit for Integrated Vector Management in Sub-Saharan Africa. Geneva; World Health Organization: Geneva, Switzerland, 2016.

57. Khan, Z.R.; Midega, C.A.O.; Pittchar, J.O.; Murage, A.W.; Birkett, M.A.; Bruce, T.J.A.; Pickett, J.A. Achieving food security for one million sub-Saharan African poor through push-pull innovation by 2020. Philos. Trans. R. Soc. B Biol. Sci. 2014, 369, 20120284. [CrossRef] [PubMed]

58. Mengistu, A. Forage development in the Ethiopian highlands. In Strategies for Development; Ministry of Agriculture: Addis Ababa, Ethiopia, 1994.

59. Kassam, A.H.; van Velthuizen, H.T.; Sloane, P.H.; Fischer, G.W.; Shah, M.M. Agro-Ecological Land Resources Assessment for Agricultural Development Planning-A Case Study of Kenya Resources Data Base and Land Productivity. In Technical Annex 5, Livestock Productivity; FAO: Rome, Italy, 1993.

60. Singh, I.; Squire, L.; Strauss, J. Agricultural Household Models: Extensions, Applications and Policy; John Hopkins University Press: Baltimore, MD, USA, 1986.

61. De Janvry, A.; Fafchamps, M.; Sadoulet, E. Peasant household behaviour with missing markets: Some paradoxes explained. Econ. J. 1991, 101, 1400-1417. [CrossRef] 
62. Kassie, M.; Jabbar, M.A.; Kassa, B.; Saleem, M.A.M. Benefits of integration of cereals and forage legumes with and without crossbred cows in mixed Farms: An ex ante analysis for Highland Ethiopia. J. Sustain. Agric. 1999, 14, 31-48. [CrossRef]

63. Hazell, P.B.R.; Norton, D.R. Mathematical Programming for Economic Analysis in Agriculture; Macmillan Company: New York, NY, USA, 1986.

64. Habtemariam, T.; Howitt, R.; Ruppanner, R.; Riemann, H.P. Application of a linear programming model to the control of African trypanosomiasis. Prev. Vet. Med. 1984, 3, 1-14. [CrossRef]

65. van Dooren, C.; Tyszler, M.; Kramer, G.F.H.; Aiking, H. Combining low price, low climate impact and high nutritional value in one shopping basket through diet optimization by linear programming. Sustainability 2015, 7, 12837-12855. [CrossRef]

66. Rambeloson, Z.J.; Darmon, N.; Ferguson, E.L. Linear programming can help identify practical solutions to improve the nutritional quality of food aid. Public Health Nutr. 2008, 11,395-404. [CrossRef]

67. Kebbeh, M.; Miezan, K.M. Ex-ante evaluation of integrated crop management options for irrigated rice production in the Senegal River Valley. Field Crop. Res. 2003, 81, 87-94. [CrossRef]

68. Dupras, D.; Pinga, V.E.B.; Tessema, T. Analysis of Opportunities for Rural Non-Farm Enterprise Development and Job Creation in Chronically Food Insecure Areas in Ethiopia; USAID: Washington DC, USA, 2012

69. UN Department of Social and Economic Affairs, Population Division, UN, New York. The United Nations. A population Database. 2015. Available online: https://www.un.org/en/development/desa/population/index. asp (accessed on 8 April 2019).

70. Leta, S.; Alemayehu, G.; Seyoum, Z.; Bezie, M. Prevalence of bovine trypanosomosis in Ethiopia: A meta-analysis. Parasites Vectors 2016, 9, 1-9. [CrossRef] [PubMed]

71. Abro, Z.A.; Kassie, M.; Enchalew, B.; Tefera, T. Push-Pull Technology as a Participatory Integrated Pest Management in Southern Ethiopia: Cost-Benefit Analysis; International Centre of Insect Physiology and Ecology (icipe): Addis Ababa, Ethiopia, 2019.

72. Shaw, A.P.M.; Wint, G.R.W.; Cecchi, G.; Torr, S.J.; Mattioli, R.C.; Robinson, T.P. Mapping the benefit-cost ratios of interventions against bovine trypanosomosis in Eastern Africa. Prev. Vet. Med. 2015, 122, 406-416. [CrossRef]

(C) 2020 by the authors. Licensee MDPI, Basel, Switzerland. This article is an open access article distributed under the terms and conditions of the Creative Commons Attribution (CC BY) license (http://creativecommons.org/licenses/by/4.0/). 